\title{
Organizational Practices, Enterprise Systems, and Firm Performance
}

\author{
Arun Madapusi \\ Northeastern State University
}

This research study investigates the influence of organizational practices on firm performance in enterprise system (ES) deployments. Innovation diffusion theory was drawn upon to develop and test a model using data gathered from a sample of Indian production firms. The results indicate that ES modules impact firm performance differently, and that organizational practices play a role in influencing firm performance. The findings suggest that an organizational practices-based approach to ES deployments helps firms garner enhanced benefits from their deployments.

Keywords: Organizational Practices, Enterprise Systems, Firm Performance

\section{INTRODUCTION}

Enterprise systems (ES) are technological innovations that standardize and integrate business operations and help firms achieve "end-to-end" connectivity to improve performance (Zhu, Kraemer, \& $\mathrm{Xu}, 2006$; Davenport \& Harris, 2007). Though, firms generally reported success in their technical ES deployments, they continue to face challenges in obtaining business benefits from implementing these systems (Vemuri \& Palvia, 2006; Krigsman, 2013; Manthou, V., Stefanou, C.J., \& Tigka, K., 2018)). Studies show that firms struggled to leverage their implementations and achieve effective integration mainly due to their failure to address the people-side of ES, i.e. organizational practices (Karimi, Somers, \& Bhattacherjee, 2007; Chou \& Chang, 2008; Galliers, 2018).

Past studies (e.g., Rogers, 2003; Fichman, 2004) on innovation diffusion indicate that innovations (such as ES) impact innovation outcomes (such as firm performance). Different measures of innovation characteristics have been used to examine the diffusion of ES (and hence firm performance) such as relative advantage (Elbertsen, Benders, \& Nijssen, 2006) complexity and compatibility (Ruivo, Oliveira, \& Neto, 2012), business process reengineering (Bradford \& Florin, 2003), and extent of ES implementation (Karimi et al., 2007). Innovation diffusion literature (e.g., Quinn, Baruch, \& Zien, 1997; Rogers, 2003) suggests that innovation facilitators (such as organizational practices) influence the adoption and the diffusion of innovations. Research scholars have investigated the influence of different organizational practices on the deployment and diffusion of ES (and hence firm performance) such as communication climate (Finney, 2011), type of decision-making and decision-making processes (Ke \& Wei, 2008), professionalism of users, and the pragmatic outlook of the firm (Davenport, 2000; Wang \& Chen, 2006).

For the most part, research on innovation in general (e.g., Rogers, 2003), and ES in specific (e.g., Elbertsen et. al., 2006), have focused on determining the direct precursors (such as innovation characteristics, and innovation facilitators) of innovation, with each precursor predicted to independently 
influence performance. The interaction between the precursors of innovation such as innovation characteristics and innovation facilitators represent a less researched area (Fichman, 2004; Karimi et al., 2007). This study seeks to move forward this stream of research by focusing on the following research questions:

1. What is the relationship between innovations (ES) and innovation outcomes (firm performance)?

2. Do innovation facilitators (organizational practices) influence the relationship between innovations (ES) and innovation outcomes (firm performance)?

The rest of the paper proceeds in the following manner. First, a research model is developed to enhance understanding of an organizational practices-based systems approach that underlies ES. Next, the model is tested with survey data collected from a sample of Indian production firms that have deployed ES. Then, the results are provided from the testing of the relationship between ES implementation status and firm performance, and the influence of organizational practices in moderating the above relationship. Lastly, the implications of the findings are discussed.

\section{THEORETICAL BACKGROUND}

Diffusion is the process by which an innovation is disseminated over time among members of an organization (Rogers, 1962, 2003). Most innovations are technology-based (Rogers, 2003); hence, from a technological diffusion perspective (Cooper \& Zmud, 1990), the implementation of an ES can be considered to be an organizational effort to diffuse the innovation (i.e. ES) within the firm and its supply chain. ES help reduce uncertainty (uncertainty here means the lack of information) through their information-seeking and information processing activities (Galbraith, 1977; Rogers, 2003). ES are "packages" of innovations (i.e. "packages" of ES modules) that are closely interrelated and the information flows that connect the various systems elements (i.e. ES modules) help reduce uncertainty. Past studies suggest that firms need to exploit this "systemic" or "packages" of innovations effect to rapidly diffuse the ES (Gattiker \& Goodhue, 2004; Stratman, 2007). Galbraith (1977) and Rogers (2003) suggest that diffusions should be undertaken in a manner that exploits the capabilities of each of the system elements (i.e. ES modules) and individual participants (i.e. organizational practices). The best adaptation that would enhance performance is when firms match their features to the demands of the environment (i.e. match and leverage ES modules-organizational practices interactions).

\section{Attributes of Innovations and Innovation Outcomes}

Past studies have mostly used the characteristics or attributes of innovations to examine the diffusion of innovations and hence their impact on firm performance (Rogers, 2003; Cooper \& Zmud, 1990). Rogers (2003) considers five characteristics as most important in explaining the diffusion of innovations: relative advantage, complexity, compatibility, trialibility, and observability. The findings from his study indicate that innovations that have greater relative advantage, compatibility, trialability, and observability, and less complexity will diffuse rapidly. Relative advantage is the extent to which an innovation is perceived as better than the one it supersedes (Rogers, 2003; Cooper \& Zmud, 1990). ES possess high relative advantage as they extend manufacturing resource planning (MRP II) system's production functionalities to include other functional areas of the firm, and create smooth, continuous, and integrated information flows across the supply chain (Chou \& Chang, 2008). Compatibility is the extent to which an innovation is perceived to compare with existing values, past experiences, and the needs of potential adopters (Rogers, 2003; Bradford \& Florin, 2003). Their findings suggest that techno-social compatibility in ES deployment enhances performance; i.e. compatibility is high when technical implementations go hand in hand with appropriate change management strategies, i.e. with people and organizational-related changes.

Complexity is the degree to which an innovation is perceived as difficult to understand and use (Rogers, 2003; Elbertsen et al., 2006). Past research indicates that single module ES deployments result in firms obtaining increased organizational benefits (Hitt, Wu, \& Zhou, 2002). As firms extend the scope of 
their implementations (i.e. as complexity increases), the integration of more and more modules and effective system usage over time (i.e. the "systemic" effect reduces complexity) increases performance. Trialability is the extent to which an innovation may be experimented with on a limited basis (Rogers, 2003; Ben \& Papazafeiropoulou, 2004). ES are modular systems and firms selectively implement modules that match their business needs. The ES deployment process involves fine-tuning of modules (thereby increases trailability) so as to better align the ES functionalities to business needs. This ESbusiness needs alignment in turn enables firms to register performance benefits, such as for example, obtaining a better return on investment and garnering a competitive advantage. Observability is the extent to which the results of an innovation are visible to others (Rogers, 2003; Ruivo et al., 2012). Past studies indicate that ES deployments streamline and standardize business processes, efficiencies which firms then leverage to ensure higher customer satisfaction and enhanced profitability. The high observability of these benefits helps ensure employee buy-in to the ES and thereby increases user satisfaction.

\section{Facilitators of Innovations and Innovation Outcomes}

The attributes of innovations are an important factor in explaining the diffusion of innovations; facilitators are an equally important factor in influencing the diffusion of innovations. Rogers (2003) identifies four facilitators as affecting innovation diffusion and they are: the type of innovation decision, the nature of communication channels, the nature of the social system, and the extent of change agents' efforts. Past studies (Hofstede, Neuijen, Ohayv, \& Sanders, 1990; Soh, Kein, \& Tay-Yap., 2000; Sia, Tang, Soh, \& Boh, 2002) indicate that these four innovation facilitators are broadly subsumed under the organizational practices construct. Firms implementing ES go through a radical change process as these systems fundamentally alter the way they do business. Because of the far-reaching business ramifications of implementing these systems, it is critical that organizational practices support the needs of technology and business (Davenport, 1998; Wang et al., 2005). Their findings suggest that organizational practices exert a positive influence on firm performance.

The use of communication channels influences the diffusion of innovations (Davenport, 1993; Rogers, 2003). Their findings indicate that interpersonal (e.g., experience sharing) communication increases the diffusion of an innovation. Researchers (e.g., Finney, 2011) suggest that continuous communication within the firm, across the ES life cycle, ensures quicker acceptance and effective usage of the ES. The nature of a social system such as its work norms and people involvement affect the diffusion of innovations (Quinn, et al., 1997; Rogers, 2003). Their findings suggest that these are critical in managing employees who are linked by flows of information. Implementing ES causes major organizational transformations in firms (Hurley and Hult, 1998; Michela \& Burke, 2000; Ke and Wei, 2008). Their findings suggest that the type of decision-making and a concern for the decision-making processes influence ES deployment.

An innovation's diffusion is affected by the extent of a change agent's efforts (Davenport, 2000; Rogers, 2003). Their findings suggest that the payoff from professionals (users who serve as change agents) coupled with a market-oriented and customer-driven outlook, influences the diffusion of innovations throughout the firm. Users play a critical role in aiding and influencing ES implementations throughout their life cycles (Wang \& Chen, 2006). ES deployments demand multiple skill-sets technical, business, and people skills; hence, users who identify themselves with their jobs aid in implementation support, promote conflict resolution among ES stakeholders, and have a direct bearing on outcomes.

\section{RESEARCH MODEL}

The review of the literature, and theoretical development presented above, suggest that although an innovation (ES) deployment influences firm performance, its ability to do so is moderated by innovation facilitators (organizational practices) that are brought to bear during the ES implementation. The relationship between ES implementation and firm performance as moderated by organizational practices is presented in Figure 1. In the following section, two related hypotheses are developed. 


\section{ES Implementation and Firm Performance}

The quantity of innovations affects firm performance (Fichman, 2004; Karimi et al., 2007). Their studies suggest that measures of innovation quantity such as time since implementation, and the number of modules implemented, are linked positively to performance outcomes. Ranganathan \& Brown (2006), and Karimi et al. (2007) suggest that the extent of ES implementation influences its diffusion and impacts firm performance. Their findings suggest that as the scope of implementations increases, rapid diffusion of the ES occurs and hence firm performance increases.

\section{FIGURE 1 \\ THE RELATIONSHIP BETWEEN ES IMPLEMENTATION AND FIRM PERFORMANCE AS MODERATED BY ORGANIZATIONAL PRACTICES}

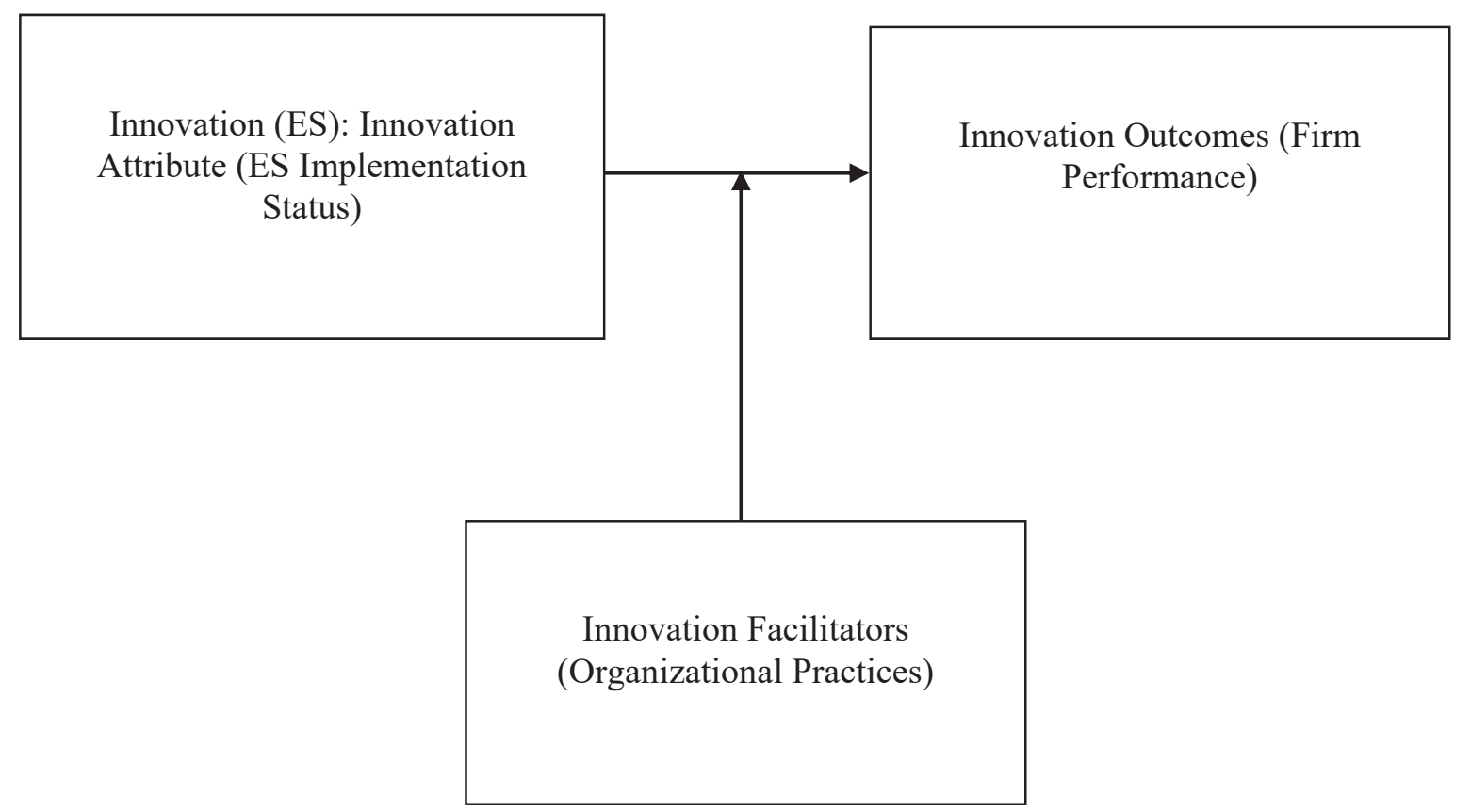

Mohrman, Galbraith, Lawler, \& Associates (1998), and Zhu et al. (2006) suggest that firms should integrate their customer-related and internal-support operations through information systems to improve performance. Their findings suggest that integrating modular systems and using them over time will further increase performance. Madapusi \& Ortiz (2014) tie implementation status, i.e. the time since implementation and number of modules implemented, to firm performance. They suggest that as implementation status increases, firm performance increases.

Other system studies such as MRP II (e.g., Duchessi, Schaninger, Hobbs, \& Pentak, 1988), Just-inTime (e.g., White \& Prybutok, 2001), and quality (e.g., Berry, 1996) studies also link innovation measures such as time since implementation and quantity implemented to firm performance. A synthesis of the above discussion, in relation to this study's objectives, suggests that firms obtain performance gains from the "implementation status" (time since implementation and number of modules) of their deployed ES modules. Hence, the first linkage in the ES implementation model in Figure 1 suggests that ES implementation status is related to firm performance.

H1: The implementation status of individual ES modules contributes to firm performance.

Diffusion is a process of social change and is required even when innovation attributes are clearly linked to performance (Rogers, 2003). Fichman (2004) indicates that innovation facilitators not only 
increase the quantity of innovation but also facilitate the translation of any given amount of innovation into positive performance impacts. Galbraith (2002), and Mohrman et al (1998) suggest that the technical deployment of organizational information systems should be supported by appropriate change management strategies, i.e. with people and organizational-related changes. Leonard-Barton (1988) and Quinn et al. (1997) suggest that innovation facilitators determine how an innovation is supported, driven, and sustained throughout its implementation. Karimi et al. (2007), and Chou \& Chang (2008) suggest that interactions between innovation attributes and innovation facilitators are critical in determining the assimilation of innovations. Their studies identify organizational practices as influencing firm performance.

Other system studies such as materials requirements planning or MRP (e.g., Anderson \& Schroeder, 1984), and Just-in-Time (e.g., Chong, White, \& Prybutok, 2001) also link innovation attributes and innovation facilitators to firm performance. A synthesis of the above discussion, in relation to this study's objectives, suggests that firms obtain performance gains when organizational practices are leveraged while deploying ES modules. Hence, the second linkage in the ES implementation model in Figure 1 suggests that organizational practices influence the relationship between ES implementation status and firm performance.

H2: Organizational practices moderate the relationship between the implementation status of individual ES modules and firm performance.

\section{METHODOLOGY}

To test the hypothesised model relationships, a survey instrument was developed, and data were obtained from a sample of Indian production firms. The survey was implemented using a mixed mode methodology (a combination of postal and email methods). The data obtained were analyzed using factor and multiple linear regression analysis.

\section{Instrument Development}

The data collection instrument was developed from ES and related systems literature. It was validated through a four-step process: (1) inputs from academicians, (2) inputs from practitioners, (3) pre-test at a graduate ES class, and (4) pre-test at a production firm deploying ES. The data collection instrument included items that assessed firm and respondent characteristics, ES implementation status, organizational practices, and firm performance.

\section{Operational Definitions}

Independent Variables

A review of the literature and ES vendors' websites yielded 14 modules that comprise the ES (Mabert, Soni, \& Venkataramanan, 2000; Francalanci, 2001; Olhager \& Selldin, 2003; Madapusi \& Ortiz, 2014; www.sap.com; www.oracle.com). The fourteen modules identified are financials, controlling, plant maintenance, materials management, production planning, project management, sales and distribution, logistics, quality management, human resources, supply chain management (SCM), customer relationship management (CRM), electronic-commerce (E-Commerce), and advanced planner optimizer/ advanced planner scheduler (APO/APS). The rating scales used to gather data on each of the modules were adapted from the Berry (1996), White, Pearson, \& Wilson (1999); and the Madapusi \& Ortiz (2014) studies. Data for each of the 14 ES modules were obtained using a scale consisting of the following ranges of implementation statuses: not implemented (NI), implementation started within the last year $(0$ to $<1$ year), implementation started 1 or more but less than 3 years ago ( 1 to $<3$ years), implementation started 3 or more but less than 5 years ago $(3$ to $<5)$, and implementation started 5 or more years ago $(5+)$. 


\section{Dependent Variables}

A survey of the literature yielded five measures for evaluating the performance of ES (Davenport, 1998; Mabert, Soni, \& Venkataramanan, 2003; Hawking \& Stein, 2004; Madapusi \& Ortiz, 2014) profitability, return on investment (ROI), competitive advantage, user satisfaction, and customer satisfaction. The data for each of the five performance measures were obtained using a 7-point Likert type scale ranging from 1 (disagree) to 7 (agree).

\section{Moderating Variables}

A review of the literature yielded six organizational practices that are believed to facilitate ES deployments (Hofstede et al., 1990; Soh et al., 2000; Sia et al., 2002; Finney, 2011; Wang \& Chen, 2006) - communication climate, job orientation, process orientation, degree of control, pragmatism, and professionalism. The data for each of these variables were obtained using a 7-point Likert type scale ranging from 1 (disagree) to 7 (agree).

\section{The Sampling Frame for the Survey}

The members of production firms that are part of the Confederation of Indian Industry (CII) formed the sample for the study $(\mathrm{n}=900)$. The member firms are from varied industries such as metals, automotive, machinery and equipment, chemicals, rubber and plastics, etc. The sample member list is representative of the Indian production sector comprising of firms of different sizes, and with varied manufacturing processes.

\section{Data Collection \& Management}

Dillman's (2000) tailored design method (TDM) for mail surveys was followed to the extent possible. The survey questionnaire was mailed out to the 900 firms. After discarding incomplete and unusable returned questionnaires, the effective sample used for analysis consisted of 203 firms (response rate: $22.56 \%)$. The sample data were compiled separately - firms surveyed in the first wave $(\mathrm{n}=115)$, and firms surveyed in the second wave $(n=88)$ - and examined. The data indicated that the response rates for demographic characteristics were similar across the two waves suggesting that there was no systematic non-response bias. Podsakoff \& Organ's (1986) suggestions for avoidance of common method bias such as scale re-ordering, using a purposive sample, survey using a multi-mode methodology were followed. Harmon's one factor post-hoc test indicated that multiple factors emerged and accounted for the variance in a factor analysis of the measures and hence common method bias was not an issue in this study.

The data were then examined and found to be suitable for conducting factor and multiple regression analyses. The correlations in the correlation matrix for the organizational practices and performance measures were greater than 0.30. The measures of sampling adequacy (Hair et al., 2006) indicated sampling was adequate and the Bartlett's tests of sphericity (Hair et al., 2006) were significant. Hence, the data were found suitable for factor analysis. The correlation matrix among the ES modules indicated the absence of multicollinearity. The regressions assumptions of linearity of the phenomena measured, constant variance of the error terms, independence of the error terms, and normality of the error term distribution (Hair et al., 2006) were then examined, and no violations were noted. A multiple regression test on demographic data indicated no model fit for the hypothesized model relationships.

\section{ANALYSIS \& RESULTS}

\section{Firm and Respondent Characteristics}

The survey questionnaire collected data on firm size, industry type, ES deployed, and respondent characteristics. The results indicate that the sample is a good representation of the Indian production sector comprising of firms of different sizes and operating in various industries. Firms with over 1000 employees formed $41 \%$ of the respondents, with an additional $25 \%$ coming from firms having between 500 and 999 employees. The most frequently represented industry type was automotive, accounting for $21 \%$ of the sample; the next being machinery and equipment accounting for $10 \%$ of the sample. Make-to- 
order was the primary production system used by $62 \%$ of the firms while $38 \%$ utilized a make-to-stock approach.

Firms which had implemented a single vendor ES accounted for $68 \%$ of the sample. SAP was deployed by $29 \%$ of the sampled firms, followed by Oracle/PeopleSoft with $10 \%$, and SSA Global/Baan and Microsoft ( $9 \%$ of the sample). About $90 \%$ of the respondents were top and middle level managers, and $92 \%$ of the respondents possessed more than 10 years of work experience. About $85 \%$ of the respondents worked in the information systems area, and $99 \%$ of the respondents possessed a bachelor's degree and above. The above profile indicates that respondents have a good knowledge of their ES at the holistic as well as the detailed implementation levels thereby increasing the validity of the study.

\section{Factor Analysis of Performance Measures}

The data for the five performance measures were factor analysed and the results are shown in Table 1. The factor loadings (using latent root criterion and scree test) indicate that all the items correctly loaded on a single five-factor solution (factor loadings exceeding .70) and accounted for more than $66 \%$ of the variance.

TABLE 1

\section{PERFORMANCE COMPONENT ANALYSIS FACTOR MATRIX}

\begin{tabular}{|l|l|}
\hline Firm Performance & Factor Loadings \\
\hline Profitability & 0.819 \\
\hline Return on Investment & 0.818 \\
\hline Competitive Advantage & 0.851 \\
\hline User Satisfaction & 0.745 \\
\hline Customer Satisfaction & 0.840 \\
\hline Cronbach's Alpha $=0.87$
\end{tabular}

\section{Factor Analysis of Organizational Practices Measures}

The data for the six organizational practices measures were factor analysed and the results are shown in Table 2. The factor loadings (using latent root criterion and scree test) indicate that all the items (except one item, job orientation, which was removed) correctly loaded on a single five-factor solution (factor loadings exceeding .64) and accounted for more than 53\% of the variance.

TABLE 2 ORGANIZATIONAL PRACTICES COMPONENT ANALYSIS FACTOR MATRIX

\begin{tabular}{|l|l|}
\hline Organizational Practices & Factor Loadings \\
\hline Communication Climate (open interchange) & 0.654 \\
\hline Process Oriented (concern for how work gets done) & 0.640 \\
\hline Degree of Control (exerts tight formal control) & 0.824 \\
\hline Pragmatic (market oriented and customer driven) & 0.800 \\
\hline Professional (identifies with type of job) & 0.708 \\
\hline
\end{tabular}

Cronbach's Alpha $=0.77$

\section{Regression Models}

Testing Hypothesis H1

Hypothesis H1 was tested by developing regression models to analyze firm performance and the results shown in Table 3 indicate partial support. As can be seen from the table, ten of the fourteen modules are significantly related to firm performance; the four modules that are non-significant are 
project system, human resources, E-commerce, and APO/APS. Among the ten significant modules, the quality management module impacts firm performance the most, and the SCM module the least.

TABLE 3

RELATIONSHIP BETWEEN ES IMPLEMENTATION STATUS AND FIRM PERFORMANCE

\begin{tabular}{|l|lll|}
\hline Implementation Status of ES Modules & \multicolumn{3}{|l|}{ Firm Performance } \\
& $\boldsymbol{\beta}$ & $\mathbf{R}^{\mathbf{2}}$ & $\mathbf{F}$ \\
\hline Financials & $0.215^{* *}$ & 0.046 & $9.780^{* *}$ \\
\hline Controlling & $0.201^{* * *}$ & 0.040 & $8.460^{* * *}$ \\
\hline Plant Maintenance & $0.245^{* * *}$ & 0.060 & $12.811^{* * *}$ \\
\hline Materials Management & $0.189^{* *}$ & 0.036 & $7.421^{* *}$ \\
\hline Production Planning & $0.238^{* * *}$ & 0.057 & $12.108^{* * *}$ \\
\hline Sales \& Distribution & $0.215^{* *}$ & 0.046 & $9.780^{* *}$ \\
\hline Logistics & $0.190^{* *}$ & 0.036 & $7.493^{* *}$ \\
\hline Quality Management & $0.248^{* * *}$ & 0.061 & $13.144^{* * *}$ \\
\hline Supply Chain Management & $0.146^{*}$ & 0.021 & $4.385^{*}$ \\
\hline Customer Relationship Management & $0.201^{* *}$ & 0.040 & $8.450^{* *}$ \\
\hline
\end{tabular}

1. $\beta$ values are standardized regression coefficients

2. Significance: $* \mathrm{p}<.05, * * \mathrm{p}<.01, * * * \mathrm{p}<.001$

3. Only significant parameter estimates shown

\section{Testing Hypothesis H2}

Hypothesis $\mathrm{H} 2$ was tested by developing regression models to analyze the influence of organizational practices and the results shown in Table 4 indicate partial support. As can be seen from the table, the results indicate a number of interactions between organizational practices and various ES modules. The interactions between organizational practices and the materials management module had the most significant impact on firm performance. The human resources module did not directly impact firm performance, however, with organizational practices as a moderator, the human resources module was found to impact firm performance.

TABLE 4

\section{INTERACTION EFFECTS OF ORGANIZATIONAL PRACTICES ON THE RELATIONSHIP} BETWEEN ES IMPLEMENTATION STATUS AND FIRM PERFORMANCE

\begin{tabular}{|l|lll|}
\hline $\begin{array}{l}\text { Interaction Effects (Organizational Practices } \\
\text { x Implementation Status of ES Modules) } \\
\text { Organizational Practices x }\end{array}$ & \multicolumn{3}{|l|}{ Firm Performance } \\
\hline Financials & \multicolumn{3}{|l|}{$\Delta \mathbf{R}^{\mathbf{2}} \Delta \mathbf{F}$} \\
\hline Materials Management & $0.622^{*}$ & 0.015 & $4.884^{*}$ \\
\hline Sales \& Distribution & $0.628^{*}$ & 0.019 & $6.107^{*}$ \\
\hline Human Resources & $0.628^{*}$ & 0.014 & $4.491 *$ \\
\hline 1. $\beta$ values are standardized regression coefficients & $0.608^{*}$ & 0.015 & $4.610^{*}$ \\
2. Significance: $* \mathrm{p}<.05, * * \mathrm{p}<.01, * * * \mathrm{p}<.001$ & & & \\
3. Only significant parameter estimates shown & & & \\
\end{tabular}




\section{DISCUSSION}

The research questions of this study were: 1) What is the relationship between innovations (ES) and innovation outcomes (firm performance)? 2) Do innovation facilitators (organizational practices) influence the relationship between innovation (ES) and innovation outcomes (firm performance)? A model was developed to answer these questions. The results indicate support for the hypothesized model; firms with different ES implementation statuses obtain differential performance benefits, and organizational practices moderate the ES implementation status-firm performance relationship. The findings of the study and a discussion on their implications for researchers and practitioners is given below.

\section{ES Implementation and Performance}

The findings suggest the existence of a positive relationship between the ES implementation status of individual modules, and firm performance. Three of the modules - financials, sales and distribution, and the materials management - were deployed the earliest (means of years since implementation 3.56 years) and exhibit a significant relationship to firm performance. Past research (e.g., Mabert et al., 2003) indicates that these three modules are the most early and frequently implemented modules in firms. The main interfaces among these modules are financials (billing, taxes and pricing, etc.), sales and distribution (outstanding receivables, pricing, etc.), and materials management (supplier invoices, payments, etc.). The systemic integration among the modules results in reciprocal interdependence, i.e. information flows forward and backward among modules (and reduces complexity).

Three modules with significant relationships to firm performance were the next early implemented modules (means of years since implementation 2.48 years) - controlling, quality management, and production planning. Firms deploying these three modules help gain acceptance for the ES by decreasing uncertainty regarding diffusion of the innovation. The controlling module, with its focus on cost control, complements the financials module and completes the deployment of the financials applications part of the ES. The production planning module covers all major logistics processes (from continuous to assemble-to-order) and manages all activities relating to the planning and the process of production. The quality management module performs key tasks associated with quality planning, assurance, and control across all business areas (i.e. across all modules).

Three modules exhibit significance relationships to firm performance and were the next early implemented modules (means of years since implementation 1.47 years) - plant maintenance, logistics, and SCM. Firms deploy these three modules as the integrated nature of the innovation requires that increasingly more within and across firm activities be brought under the ES. As the ES has diffused across the firm, most of the uncertainty about the ES has been removed and employees feel secure in deploying additional modules. The plant maintenance module facilitates total productive maintenance for a firm's plant and production facilities, and the logistics module provides the tools and reports necessary to coordinate and manage logistic applications. Past research (e.g., Hendricks, Singhal, \& Stratman, 2007) suggests that the SCM module is implemented after the ES deployment has stabilized, and firms are ready to extend the ES to their supply chain partners. The real-time planning capabilities in the SCM module ensures better operational and business planning and helps firms effectively handle supply and demand changes.

The CRM module is the lone module with a significant relationship to firm performance that was most recently implemented (mean of years since implementation 0.38 years). The SCM module enables firms to reap efficiencies from downstream supply chain processes; firms then implement the CRM module to tap into the potential for achieving a greater level of customer satisfaction through gaining efficiencies in the upstream supply chain processes. The complexity associated with the CRM module's deployment and usage (as CRM interfaces with a variety of firms' clients, with diverse needs, and hence requires extensive adaptation/configuration) results in a relatively less than rapid diffusion of this module. 


\section{Moderating Role of Organizational Practices}

As mentioned earlier, the findings suggest that organizational practices influence the ES implementation status-firm performance relationship. There are a number of instances where interactions positively influence existing relationships as well as where the addition of the interaction term led to significant relationships with performance even though the ES module implementation status alone had not been significant with firm performance.

\section{Organizational Practices}

Organizational practices are visibly present among members in a firm (Hofstede et al., 1990; Kappos \& Rivard, 2008). Rogers (2003) indicates that a technological diffusion is more of a social process than a technical matter, and that rapid diffusion occurs when the innovation is compatible with organizational practices. Quinn et al. (1997) suggests that that continual innovation deals with the full life cycle of innovation; i.e. involves managing multiple deployments at different phases of the innovation's life cycle, and hence requires sustained organizational support.

There were positive interactions between organizational practices and four modules on firm performance. The interaction effects with the financials, materials management, and the sales and distribution modules suggests that the interdependence among the modules is influenced by organizational practices. The financials module interfaces with every other ES module (example, materials management module - supplier invoices, payments, etc., and sales and distribution module outstanding receivables, pricing, etc.). The sales and distribution module interfaces with the materials management module (example, availability checking and reorder points), and the materials management module interfaces with the sales and distribution module (example, material shipments and scheduling deliveries). Such reciprocal interdependence of information flows across modules binds the different modules' users together and contributes to the attainment of a critical mass beyond which the diffusion of the ES is self-sustaining.

A significant interaction was detected between organizational practices and the human resources module. This is an intriguing interaction effect as the human resource module by itself didn't affect firm performance. In continual innovations that involve multiple deployments there is an ebb and flow of diffusion as module deployments are ended, started, customized, exploited, upgraded, etc. (Quinn et al., 1997). The above positive interactional relationship suggests that a sustained focus on organizational practices is required to go beyond achieving tactical benefits (for example, payroll automation in the human resources module) and strategically leverage module capabilities (for example, talent management in the human resources module). 


\section{CONCLUSION}

In this study, a research model was developed to examine the ES implementation status-firm performance relationship, and the influence of organizational practices on the above relationship. The results indicate that the ES implementation statuses of different modules provide differential performance benefits to firms; and organizational practices influence the ES implementation status-firm performance relationship. The findings suggest that an organizational practices-based (i.e. a people-based) approach to ES deployments helps firms obtain increased benefits from their deployments.

From a research perspective, this study contributes to the diffusion of innovations literature by embedding ES implementations within an innovation diffusion framework. Past research typically considers the direct impact of one or more innovation attributes and/or innovation facilitators on the rate of adoption. This study moves this research stream forward by considering the innovation attributeinnovation facilitator interaction effect on innovation outcomes. From a practitioner perspective, the study suggests that managers should focus on organizational practices so that the diffusion quickly attains critical mass.

Future studies could use longitudinal designs to capture the lagged ES usage-firm performance effects. Such longitudinal studies would also help in the matching of ES configurations to different business environments and provide a roadmap for firms to adapt their ES to changing business conditions. More fine-grained analysis is required to examine the lack of interactions between organizational practices and various modules, and the lack of a relationship between various modules (project management, human resources, E-Commerce, and APO/APS), and firm performance. This study provides a parsimonious measure of innovativeness as well as organizational practices that influence ES deployments. Future research should also consider other measures of innovativeness, other organizational factors, and interactions between them, so that a more comprehensive model of ES implementation emerges. 


\section{REFERENCES}

Anderson, J.C., \& Schroeder, R.G. (1984). Getting Results from your MRP System. Business Horizons, 27(3), 57-64.

Ben, L., \& Papazafeiropoulou, A. (2004). Reasons behind ERP Package Adoption: A Diffusion of Innovations Perspective. ECIS 2004 Proceeding, Retrieved September 15, 2019, from http://aisel.aisnet.org/ecis2004/80.

Berry, R.W. (1996). An Investigation of the Relationship between World Class Quality System Components and Performance. Doctoral Dissertation, University of North Texas.

Bradford, M., \& Florin, J. (2003). Examining the Role of Innovation Diffusion Factors on the Implementation Success of Enterprise Resource Planning Systems. International Journal of Accounting Information Systems, 4(3), 205-225.

Chong, H., White, R.E., \& Prybutok, V. (2001). Relationship among Organizational Support, JIT Implementation, and Performance. Industrial Management \& Data Systems, 101(5/6), 273-280.

Chou, S.W., \& Chang, Y.C. (2008). The Implementation Factors that Influence the ERP (Enterprise Resource Planning) Benefits. Decision Support Systems, 46(1), 149-157.

Cooper, R.B., \& Zmud, R.W. (1990). Information Technology Implementation Research: A Technological Diffusion Approach. Management Science, 36(2), 123-139.

Davenport, T.H. (1993). Process Innovation: Reengineering Work Through Information Technology. Boston: Harvard Business School Press.

Davenport, T.H. (1998). Putting the Enterprise into the Enterprise System. Harvard Business Review, 76(4), 121-131.

Davenport, T.H. (2000). Mission Critical: Realizing the Promise of Enterprise Systems. Boston: Harvard Business School Press.

Davenport, T.H., \& Harris, J.G. (2007). Competing on Analytics: The New Science of Winning. Boston: Harvard Business School Press.

Dillman, D.A. (2000). Mail and Internet Surveys: The Tailored Design Method. NY: John Wiley \& Sons.

Duchessi, P., Schaninger, C.M., Hobbs, D.R., \& Pentak, L.P. (1988). Determinants of Success in Implementing Materials Requirement Planning (MRP). Journal of Manufacturing \& Operations Management, 1(3), 263-304.

Elbertsen, L., Benders, J., \& Nijssen, E. (2006). ERP Use: Exclusive or Complemented? Industrial Management \& Data Systems, 106(6), 811-824.

Fichman, R.G. (2004). Going beyond the Dominant Paradigm for Information Technology Research: Emerging Concepts and Methods. Journal of the Association for Information Systems, 5(8), 314355.

Finney, S. (2011). Stakeholder Perspective on Internal Marketing Communication: An ERP Implementation Case Study. Business Process Management Journal, 17(2), 311-331.

Francalanci, C. (2001). Predicting the Implementation Effort of ERP Projects: Empirical Evidence on Sap R/3. Journal of Information Technology, 16(1), 33-48.

Galbraith, J.R. (1977). Organization Design. Philippines: Addison-Wesley Publishing Company Inc.

Galbraith, J.R. (2002). Designing Organizations: An Executive Guide to Strategy, Structure, and Process. New York: John Wiley \& Sons Inc.

Galliers, R.D. (2018). Information Systems in Global Organizations: Unpacking "Culture.” In Krishna, S. \& Madon, S, (Eds.), The Digital Challenge: Information Technology in the Development Context, New York: Routledge.

Gattiker, T.F., \& Goodhue, D.L. (2004). Understanding the Local-level Costs and Benefits of ERP through Organizational Information Processing Theory. Information and Management, 41(4), 431-443.

Hair, J.F., Black, B., Babin, B., Anderson, R.E., \& Tatham, R.L. (2006). Multivariate Data Analysis, 6th Edition, Ohio: Pearson. 
Hawking, P., \& Stein, A. (2004). Revisiting ERP Systems: Benefit Realization. Proceedings of the 37th. Hawaii International Conference on System Sciences, IEEE, 1-8.

Hendricks, K.B., Singhal, V.R., \& Stratman, J.K. (2007). The Impact of Enterprise Systems on Corporate Performance: A Study of ERP, SCM, CRM System Implementations. Journal of Operations Management, 25(1), 65-82.

Hitt, L.M., Wu, D.J., \& Zhou, X. (2002). Investment in Enterprise Resource Planning: Business Impact and Productivity Measures. Journal of Management Information Systems, 19(1), 71-98.

Hofstede, G., Neuijen, B., Ohayv, D.D., \& Sanders, G. (1990). Measuring Organizational Cultures: A Qualitative and Quantitative Study across Twenty Cases. Administrative Science Quarterly, 35(2), 286-316.

Hurley, R.F., \& Hult, G.T.M. (1998). Innovation, Market Orientation, and Organizational Learning: An Integration and Empirical Examination. Journal of Marketing, 62(3), 42-54.

Kappos, A., \& Rivard, S. (2004). A Three-Perspective Model of Culture, Information Systems, and Their Development and Use. MIS Quarterly, 32(3), 601-634.

Karimi, J., Somers, T.M., \& Bhattacherjee, A. (2007). The Impact of ERP Implementation on Business Process Outcomes: A Factor-Based Study. Journal of Management Information Systems, 24(1), 101-134.

Ke, W., \& Wei, K.K. (2008). Organizational Culture and Leadership in ERP Implementation. Decision Support Systems, 45(2), 208-218.

Krigsman, M. (2013). Compelling Advice for the CFO. ZDNet. Retrieved September 15, 2019, from https://www.zdnet.com/article/2013-erp-research-compelling-advice-for-the-cfo/.

Leonard-Barton, D. (1988). Implementation Characteristics of Organizational Innovations: Limits and Opportunities for Management Strategies. Communication Research, 15(5), 603-631.

Mabert, V.A., Soni, A., \& Venkataramanan, M.A. (2000). Enterprise Resource Planning Survey of US Manufacturing Firms. Production and Inventory Management Journal, 41(2), 52-58.

Mabert, V.A., Soni, A., \& Venkataramanan, M.A. (2003). Enterprise Resource Planning: Managing the Implementation Process. European Journal of Operational Research, 146, (2), 302-314.

Madapusi, A., \& Ortiz, D. (2014). The Influence of Technical Competence Factors in ERP System Implementations. Journal of Applied Business and Economics, 16(2), 27-39.

Manthou, V., Stefanou, C.J., \& Tigka, K. (2018). The Evaluation of Business Performance in ERP Environments. In I. Management Association (Ed.), Operations and Service Management Concepts, Methodologies, Tools, and Applications (633-641). Hershey, PA: IGI Global.

Michela, J.L., \& Burke, W.W. (2000). Organizational Culture and Climate Transformations for Quality and Innovation. In N.M. Ashkanasy, C.P.M. Wilderom, and M.F. Peterson (Eds.), Handbook of Organizational Culture and Climate. Thousand Oaks, CA: Sage.

Mohrman, S.A., Galbraith, J.R., Lawler III, E.E., \& Associates. (1998). Tomorrow's Organization: Crafting Winning Capabilities in a Dynamic World. San Francisco: Jossey-Bass Inc.

Olhager, J., \& Selldin, E. (2003). Enterprise Resource Planning Survey of Swedish Manufacturing Firms. European Journal of Operational Research, 146(2), 365-373.

Podsakoff, P.M., \& Organ, D.W. (1986). Self-reports in Organizational Research: Problems and Prospects. Journal of Management, 12(4), 531-544.

Quinn, J.B., Baruch, J.J., \& Zien, K.A. (1997). Innovation Explosion: Using Intellect and Software to Revolutionize Growth Strategies. NY: The Free Press.

Ranganathan, C., \& Brown, C.V. (2006). ERP Investments and the Market Value of Firms: Towards an Understanding of Influential ERP Project Variables. Information Systems Research, 17(2), $145-161$.

Rogers, E.M. (1962). Diffusion of Innovations. New York: Free Press.

Rogers, E.M. (2003). Diffusion of Innovations. New York: Free Press.

Ruivo, P., Oliveira, T., \& Neto, M. (2012). ERP Use and Value: Portuguese and Spanish SMEs. Industrial Management \& Data Systems, 112(7), 1008-1025. 
Sia, S.K., Tang, M., Soh, C., \& Boh, W.F. (2002). Enterprise Resource Planning (ERP) Systems as a Technology of Power: Empowerment or Panoptic Control? Database for Advances in Information Systems, 33(1), 23-37.

Soh, C., Kien, S.S., \& Tay-Yap, J. (2000). Cultural Fits and Misfits: Is ERP a Universal Solution? Communications of the ACM, 43(4), 47-51.

Stratman, J.K. (2007). Realizing Benefits from Enterprise Resource Planning: Does Strategic Focus Matter? Production and Operations Management, 16(2), 203-216.

Vemuri, V. K., \& Palvia, S.C. (2006). Improvement in operational efficiency due to ERP Implementation: Truth or Myth? Information Resources Management Journal, 19(2), 18-36.

Wang, E., \& Chen, J. (2006). Effects of Internal Support and Consultant Quality on the Consulting Process and ERP System Quality. Decision Support Systems, 42(2), 1029-41.

Wang, E., Chou, H.W., \& Jiang, J. (2005). The Impacts of Charismatic Leadership Style on Team Cohesiveness and Overall Performance during ERP Implementation. International Journal of Project Management, 23(3), 173-180.

White, R.E., Pearson, J.N., \& Wilson, J.R. (1999). JIT Manufacturing: A Survey of Implementations in Small and Large US Manufacturers. Management Science, 45(1), 1-15.

White, R.E., \& Prybutok, V. (2001). The Relationship between JIT Practices and Type of Production System. Omega, 29(2), 113-124.

Zhu, K., Kraemer, K.L., \& Xu, S. (2006). The Process of Innovation assimilation by Firms in Different Countries: A Technology Diffusion Perspective on E-Business. Management Science, 52(10), 1557-1576. 